\title{
Babson's Signature Entrepreneurship Course
}

\author{
Yasuhiro (Yasu) Yamakawa (Babson College)
}

KEYWORDS: Entrepreneurship, Teaching Methods, student entrepreneurs, Student innovators.

Babson College's flagship undergraduate course, "Foundations of Management and Entrepreneurship (FME)," was created in 1996 (as Foundation Management Experience) to give all first year undergraduate students the experience of starting and managing a business. The course is built on the philosophy of Founder Roger Babson and his vision that "it makes no sense to study business management until you understand business creation." Since its inception, FME has become the entrepreneurial foundation of the college and its first year undergraduate immersion into the world of entrepreneurship. It has evolved into a rite of passage for all undergraduates and the cultural/curriculum core at Babson, blending theory and practice.

Over the years, a wide array of non-tech and high-tech entrepreneurial initiatives have been developed through FME - from product and service-based businesses to events and social gatherings. Student ventures have included refrigerator odor neutralizers containing used coffee grounds (Fridge-Pal); partnering with a local beekeeper to produce and package honey (Babson Honey); utilizing Near-Field Communication (NFC) devices programmed to transfer users' desired contact information from a card to a smartphone (Tap Tag); and showing classic and newly released movies on campus (Second Take Cinema). Through the FME experience, students have learned about technology, licensing and legal issues such as obtaining permits in highly regulated markets -- along with the nuts and bolts of running and managing a business while creating economic and social value.

FME is a required course for all first-year undergraduate students. This means every student experiences the entire cycle of entrepreneurship: identifying an opportunity, developing the concept, determining the resource requirements, acquiring the resources, managing the business, harvesting and exiting the venture. In a nutshell, students in teams learn what it takes to start and run a business.

\section{Major Learning Objectives}

The overall objective of FME is to teach students the basics of business in an entrepreneurship container, and how to create economic and social value. The course helps students:

\section{Experience the nature of business as an} integrated enterprise

2. Practice entrepreneurial thought and action

3. Identify, develop and assess entrepreneurial opportunities that create social and economic value

4. Analyze local and global context as it relates to entrepreneurial opportunities

5. Explore the self, teams and organizations in relation to entrepreneurial leadership

Learning in FME can be characterized by its just-in-time nature (i.e., tools provided right when students need them in the start-up process), and its proactive and experiential nature (i.e., try then apply, and trial and error mentality). The paradigm is shifted from "learn, then do" to "do, then learn." The fundamental learning model is: action - reflection - application. In FME, "action trumps everything."

FME provides at least two other learning opportunities. Community service projects allow students to work with a partner to provide service to a not-for-profit organization, and to consider how they might help in addressing social problems and creating social value. In the Coaching for Leadership and Teamwork Program (CLTP), all students participate in an activity-based event for a chance to receive feedback on their leadership, teamwork, decision-making and communication skills as well as their ethical awareness in business situations.

\section{The Experience}

Each year, approximately 500 first-year undergraduate students (the entire freshman class) are enrolled in 
approximately 13 sections with approximately 40 students each, two faculty members (from different management disciplines: one who leads the entrepreneurship/marketing stream, and the other who leads the organizational behavior stream), and two student mentors (from sophomores to seniors who have previously taken the course). Approximately 13 faculty members with core expertise in entrepreneurship, marketing, information technology, organizational behavior, accounting and finance are involved in teaching, coordinating and running the course. FME is a two-semester, 7-credit course (3 in the fall, 4 in the spring), and class meets two days per week (typically Mondays/Wednesdays or Tuesday/Thursdays). Exams and workshops (e.g., prototyping) occur on Fridays.

The steps in the entrepreneurial process are separated into three distinct phases: explore, pursue, and launch and grow. Typically, the explore and pursue phases take place in the fall semester, then the launch and grow phase takes place in the spring semester.

\section{Explore phase}

In this phase, students build four teams of approximately 10 members. Students learn how to generate ideas and identify opportunities, while exploring personal values and interests. At the end of the phase, each explore team will generate $2-3$ business ideas using concepts/framework/tools and gauging the potential to create economic and social value. Teams will "rocket pitch" (3 minutes 3 slides) their ideas, and ideas are then evaluated based on their readiness and potential - whether the idea is worth moving forward to the next phase.

\section{Pursue phase}

In this phase, students focus on assessing the feasibility of ideas using fundamental marketing principles and market research tools. More specifically, for each proposed business idea, teams conduct (a) qualitative and quantitative research to assess the potential market, (b) pro-forma financial projections, and (c) social, environmental, economic responsibility and sustainability assessment for its supply chain. The result of these efforts will be gathered into a feasibility presentation (a 10-minute presentation plus 10-minute $\mathrm{Q} \& A)$. For businesses deemed ready to move forward (typically 2-3 businesses per section), students build on organizational behavior concepts to design and choose the leadership structure for their proposed start-ups. At the end of the phase, each business team files a request for funding (typically the team receives an initial loan of up to $\$ 3,000$ from the College to start and run the business), then creates and presents a launch plan for the next phase.

\section{Launch and grow}

In this phase, students run and manage their businesses while continuing to learn about business operations, financial controls, marketing communications and social media, and other facets of entrepreneurship. Students further build capabilities in working together, leveraging diversity, functioning as a team, exercising positive influence, and dealing with conflict and ethical challenges. At the end of the phase, all businesses close down and go through financial audits. All profits are donated to a community service organization chosen by each business. Each student must also spend six hours working with the chosen community service organization. Each team will wrap up the year-long experience with a report to Babson community, also known as the business "legacy" presentation - an opportunity to reflect on what they learned about business, careers and themselves.

The process of developing, launching, founding, running, managing, and harvesting a business creates a real-world context to teach students the basics of business including (in alphabetical order): accounting, finance, human resources, information technology, marketing and sales, organizational behavior, operations, etc. Using entrepreneurship as an organizing framework, Babson teaches students general management skills. As mentioned earlier, session topics are introduced in a specific sequence that matches the start-up process. Topics are taught on an as-needed basis so that students are prepared for each stage of their experience.

\section{The Outcome}

On average, revenue and profit for FME businesses are $\$ 7,300$ (USD) and $\$ 1,900$ (USD) respectively (compiled from 16 businesses in spring 2008). More importantly, through the FME experience, students have made a profound impact on local communities. Since its inception, FME businesses have donated nearly half a million dollars to more than 75 organizations (as of spring 2016). Students have dedicated more than 45,000 hours to these organizations. Clearly, through the FME experience, Babson has reinforced the importance of giving back to the community - an important stakeholder of every business. 
Students learn from FME what we cannot easily teach:

- Time management and prioritization are critical.

- One hour of planning saves 10 hours of implementation.

- It's important not only to plan, but also to follow up.

- Poor communication is the source of most conflict.

- Decisions are made using data (e.g., market research) and sometimes gut feeling. Both are important.

- Accounting is important (e.g., how to lose and find cash).

- Feedback is our friend, but working with and evaluating peers can be much more difficult than imagined.

- Leadership... it's tough.

- Failure is good!

Students often relate the FME experience to a roller coaster ride. Through the ups and downs of entrepreneurship students learn about the sweat equity associated with a start-up. The most profound value from FME may be its impact on students' future endeavors. FME business settings are analogous to realworld business exposures that lead to future learning. All students will have had a chance to experience what it takes to found and manage a business -- in particular, working in teams, a significant experience in which to apply new learning.

Many of the course appraisals from students explain it best:

"FME has not only taught me so much about business, but it has made me a much stronger, patient, and understanding person... The course taught me how to positively deal with conflict, while also still looking out for the best for our company. I know my company had its fair share of bumps, but I would not trade anything. The fact is that because of these bumps, I walked away learning SO much more than I would have if everything went smoothly... The enthusiasm, organized teaching style, and passion shines through the lectures. I never struggled to feel engaged and interested during class, because you always knew how to grab out attention! - J.R. (2011)"

"There are not enough words with which I can describe my appreciation for my FME Experience. I had heard a lot about FME being a GPA pull-down, a source of immense stress and it also being not as good as it is made out to be. The advice that I also received was become anything, but CEO... Today, at the end of freshman year, I am happy to say that all those things that I heard were completely wrong. I could not have asked for a better FME Experience. Be it in terms of professors, student mentors, classmates and most importantly the team... all I can say is that I am thankful, although that is not enough to do justice to the amount I have learned - V.A. (2011)"

"I have learned so much about myself and where I would like to go in the future... The FME experience made me realize my dream of becoming an entrepreneur. I greatly appreciate the cultivation of the entrepreneurship mindset... This class has made my first year at Babson significant and already memorable - R.J. (2013)"

Babson College prepares students to identify opportunities and to initiate actions that create economic and social value. FME is not just a standalone entrepreneurship course. It is a vital core, a flagship course that integrates all undergraduate courses representing the college's institutional commitment to entrepreneurship education and supporting the college's mission of educating entrepreneurial leaders who change the world. FME is an entry point, a stepping stone and cornerstone for students to take on the entrepreneurial endeavors and challenges of changing the world.

\section{How to Start a Similar Program}

In order to get a program like FME off the ground, and to effectively run a program like FME, a high level of commitment, coordination, and communication is needed from multiple parts of the college. At Babson, we have created (and are still perfecting) the FME infrastructure that allows effective support (e.g., funding, mentoring) from various sources. These include (and are not limited to):

- Babson faculty with core expertise in various disciplines that meet regularly to plan and discuss course content, delivery, and policies;

- An academic services office that is the central artery of FME operations, handles logistics of the bank and coordinates start-up and closedown activities;

- College attorneys; 
- Departments such as IT and service, human resources, marketing, public safety, facilities and others.

\section{More ideas}

College business professors looking for more ideas to enrich the classroom experience can find them here (https://eiexchange.com/eix-in-class) .

Additional Search Terms: entrepreneurship courses, teaching ideas, teaching resources, classroom ideas, entrepreneurship classes, business schools, business school classes, entrepreneurship students, professors 